\title{
Avaliacãa das Políticas Públicas de Convivência com os Efeitos da Seca na Zona Rural do Povoado de Barra Nova, Várzea do Poça, Bahia
}

\section{Evaluation of the Public Policy of Coexistence Stimulus with the Effects of Drou- ght in Rural Village Around Barra Nova, Várzea do Poço City, Bahia}

Johnny Gomes de Oliveira*

\begin{abstract}
Resumo:
O presente artigo faz referência ao estudo avaliativo das políticas públicas de estímulo a convivência com os efeitos da seca no semiárido tendo como base a zona rural do entorno do povoado de Barra Nova, Várzea do Poço - BA. As políticas públicas de convivência com os efeitos das secas, representadas principalmente pelas tecnologias sociais de convivência com o semiárido, têm proporcionado às famílias beneficiadas, sobretudo as mais carentes, uma melhoria nas condições de vida, capacitando-as para conviverem harmonicamente com os períodos de estiagem. Os procedimentos metodológicos foram: levantamento de referencial bibliográfico e pesquisa de campo com a realização de registros fotográficos e entrevistas com os moradores da localidade e gestores dessas políticas no local.
\end{abstract}

\begin{abstract}
:
This paper refers to the evaluation study of the public policy of coexistence stimulus with the effects of drought in the semiarid region based on the rural village around Barra Nova, Várzea do Poço city. The public policy of coexistence with the effects of drought, mainly represented by the so-called social coexistence technologies with the semiarid region, have provided to beneficiary families, especially the neediest, an improvement in living conditions, enabling them to live together harmonically with the dry periods. The methodological procedures were: survey of bibliographic references and field research with the realization of photographic records and interviews with residents and some of those responsible for the management of these policies in place.
\end{abstract}

* Mestrando em Educação e Diversidade pela Universidade do Estado da Bahia (UNEB); especialista em Desenvolvimento Sustentável no Semiárido com ênfase em recursos hídricos pelo Instituto Federal de Educação, Ciência e Tecnologia, (IFbaiano). Professor de Geografia e vice diretor do Colégio Estadual Governador Antônio Carlos Magalhães.

Palavras-chave:

Semiárido,

Convivência com a seca Políticas públicas,

Tecnologias sociais

Key-Words:

Semiarid, Dealing with drought, Public police, Social technologies 


\section{INTRODUÇÃO}

$\mathrm{O}$ semiárido brasileiro é uma região caracterizada pelas perdas constantes dadas às desfavoráveis condições climáticas, baixos índices pluviométricos e a grande concentração de pessoas de baixa renda. De acordo com PINTO e LIMA (2005) nos últimos anos tem ocorrido uma intensificação das ações de políticas públicas, que buscam estabelecer a boa convivência da população do semiárido através da superação dos impactos sociais causados pelos efeitos das secas e ao mesmo tempo de despertar as potencialidades dessa região do país.

A população residente nessa faixa do país convive cotidianamente com o problema da escassez de chuvas. Tal condição influi diretamente no caráter socioeconômico, sobretudo daqueles que dependem economicamente das atividades agropecuárias. Nesse contexto, a população mais carente, devido à falta de recursos financeiros para investimentos maciços em infraestrutura para a captação e armazenamento de água, tende a sofrer de forma mais drástica os efeitos da estiagem.

As políticas públicas de convivência desenvolvidas na região do semiárido são disseminadas pelos de órgãos estatais e apresentam uma nova perspectiva para a população local, principalmente aquelas pessoas que têm suas vidas afetadas direta ou indiretamente pelos efeitos da estiagem. Elas evidenciam principalmente a ação do Estado na busca por soluções para a boa vivência da população nessa faixa do nosso país, que nos últimos anos tais através a minimização dos prejuízos causados pelas secas. Dentre as políticas públicas direcionadas para essas populações clientela destacam-se as tecnologias sociais de captação e armazenamento de água que objetivam guardar água proveniente das chuvas e armazená-la para usos diversos nos períodos de estiagem, sobretudo para o consumo humano e animal.

As políticas de convivência com o semiárido são positivas na medida em que possibilitam o desenvolvimento de uma relação harmoniosa entre a população local e o seu espaço de convivência. Por meio s suas práticas, essas políticas auxiliam principalmente agricultores e pecuaristas do semiárido a desenvolverem suas atividades socioeconômicas continuadamente sem haver sérios prejuízos por conta da estiagem.

Além de beneficiarem diretamente a população com algum tipo de infraestrutura física, muitas das ações de políticas públicas são acompanhadas formações, inter- câmbios, fornecimento de insumos, etc. Nesse contexto, tornam-se mais eficientes no desenvolvimento de atividades produtivas e consequentemente podem contribuir para o sustento de muitas famílias do semiárido.

O referencial teórico teve como base as discussões, acerca das características do semiárido e as potencialidades de convivência nessa região, de autores como: Campos (2014) Chacon e Bursztyn (2005), Gnadlinger (2015), Heidemann (2010), Moraes e Curado (2004), Pinto e Lima (2005), Reis (2016), Secchi (2010), Silva (2003), Souza (2006), dentre outros.

Tendo compreendido de modo geral a relevância das políticas para o trabalho de estímulo à convivência da população com os efeitos da seca, precisamos avaliar a eficiência das mesmas na prática, para isso pretende-se através dessa pesquisa refletir sobre como essas políticas públicas tem contribuído para a convivência com os efeitos das secas na zona rural do povoado de Barra Nova, localizado em Várzea do Poço, Bahia. O povoado é rodeado de pequenas propriedades rurais que desenvolvem a agricultura familiar e a pecuária em pequena escala de produção, voltadas basicamente para a subsistência dos pequenos produtores.

\section{POLÍTICAS PÚBLICAS E A CONVIVÊNCIA COM O SEMIÁRIDO}

Nas últimas décadas temos identificado no nosso país uma grande abertura de assistência direta por parte do Estado à população, sobretudo à parcela mais carente, promovida pelas chamadas políticas públicas. De modo geral, podemos afirmar que estas políticas são importantes norteadoras de ações e decisões, partidas principalmente do Estado, com o intuito de oferecer soluções para a resolução dos problemas enfrentados por uma parcela da sociedade.

Ao buscarmos uma definição para o termo política pública, nos deparamos com um leque de definições. Para esse conceito de múltiplas definições Secchi (2010) ressalta que qualquer definição apresentada para o termo política pública é considerada arbitrária, pois nota-se que não há um consenso na literatura especializada sobre seus questionamentos básicos. Souza (2006) discute algumas das principais acepções do termo política pública a apresenta a sua, definindo-a como o:

Campo do conhecimento que busca, ao mesmo tempo, "co- 
locar o governo em ação" e/ou analisar essa ação (variável independente) e, quando necessário, propor mudanças no rumo ou curso dessas ações e ou entender por que o como as ações tomaram certo rumo em lugar de outro (variável dependente). Em outras palavras, o processo de formulação de política pública é aquele através do qual os governos traduzem seus propósitos em programas e ações, que produzirão resultados ou as mudanças desejadas no mundo real. (SOUZA, 2006, p. 13).

O conceito de política pública apresentado por Souza (2006) está vinculado às intervenções exercidas pelo Estado para as mudanças desejadas. O Estado, nesse caso, age conforme as necessidades e as políticas públicas devem ser entendidas como o Estado em ação (Gobert, Muller, 1987); por meio delas ele (o Estado) desenvolve ações direcionadas para setores específicos da sociedade.

A gestão das políticas públicas são aqui entendidas como de responsabilidade do Estado, e suas práticas e manutenção se dão a partir de um processo de tomada de decisões que envolvem órgãos públicos e diferentes organismos e agentes da sociedade relacionados à política implementada. Neste sentido, as políticas públicas não podem ser reduzidas a políticas estatais, pois abrange outras esferas além do Estado (Höfling, 2001)

Consideramos as políticas públicas como fornecedoras de importantes subsídios para o desenvolvimento da população beneficiada. Atualmente essas políticas são consideradas primordiais para todos os setores da sociedade, pois prestam ampla assistência mediante as necessidades apresentadas. Para Heidemann (2010) as políticas públicas devem ter uma abordagem multicêntrica. Nessa abordagem o mais importante não é aquele que elabora a política, mas sim a origem do problema a ser enfrentado, ou seja, aqueles que serão beneficiados por essas políticas. Para a abordagem multicêntrica:

A perspectiva de política pública vai além da perspectiva de políticas governamentais, na medida em que o governo, com sua estrutura administrativa, não é a única instituição a servir à comunidade política, isto é, a promover "políticas públicas". (HEIDEMANN, 2010, p.31)

Podemos então considerar, sobre essa abordagem que a essência da política é o problema público, e, portanto, é para o público que as atenções deverão estar voltadas.

No que diz respeito ao semiárido brasileiro e ao constante problema das secas, podemos identificar nessa região uma forte atuação das políticas públicas, que dentre outras finalidades buscam estabelecer uma boa convivência da população nessa localidade, mediante as condições relacionadas à escassez de chuvas. Esse movimento representa um grande avanço nas políticas públicas direcionadas a essa faixa do nosso país, que por muito tempo teve seus problemas sociais e climáticos naturalizados.

A questão das políticas públicas de "combate" e convivência com as secas na região do semiárido passou por grandes e acentuadas transformações ao longo dos dois últimos séculos. No período colonial e no primeiro império as secas ocasionaram incalculáveis prejuízos e mortes nos sertões, mesmo assim não eram considerados um problema que merecesse políticas públicas por parte da Coroa. Atualmente reconhecemos que os programas sociais implantados pelos governos ao longo dos últimos anos diminuíram expressivamente os impactos sobre as populações do semiárido. (CAMPOS, 2014).

De acordo com dados oficiais do Ministério da Integração, a região do semiárido brasileiro abrange uma área de 969.589,4 km² que compreende o número de 1.133 municípios localizados em nove estados do Brasil: Alagoas, Bahia, Ceará, Minas Gerais, Paraiba, Pernambuco, Piauí, Rio Grande do Norte e Sergipe. Observe o mapa da figura 1.

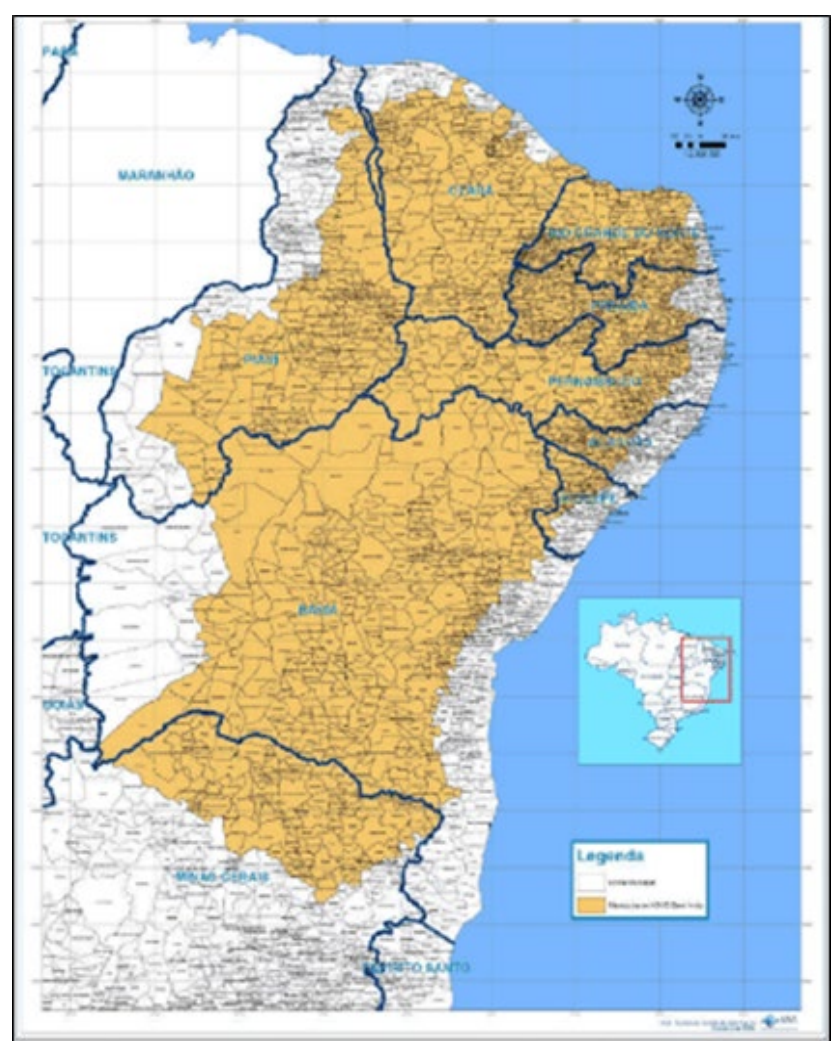

Figura1: - Nova delimitação do semiárido brasileiro Fonte: Ministério da Integração Nacional (2005).

Os problemas climáticos dessa região se dão principalmente pela condição climática semiárida. De acordo com 
dados apresentados pela SUDENE (Superintendência do Desenvolvimento do Nordeste) esta região é:

\begin{abstract}
Formada pelo conjunto de lugares contíguos, caracterizados pelo balanço hídrico negativo, resultante de precipitações médias anuais iguais ou inferiores a $800 \mathrm{~mm}$, insolação média de $2.800 \mathrm{~h} / \mathrm{ano}$, temperaturas médias anuais de $23 \mathrm{o}$ a $27 \mathrm{o} \mathrm{C}$, evaporação de $2.000 \mathrm{~mm} /$ ano e umidade relativa do ar média em torno de $50 \%$. Caracteriza-se essa região por forte insolação, temperaturas relativamente altas e pelo regime de chuvas marcadas pela escassez, irregularidade e concentração das precipitações num curto período de apenas três meses. (SUDENE, 1980).
\end{abstract}

Os índices anuais de evaporação superiores aos de pluviosidade, associados às irregularidades do período de chuvas e a reduzida capacidade de retenção de água na maioria dos solos, dentre outros demais fatores, contribuem para que o problema da seca na região do semiárido seja um problema contínuo, e sem aparente resolução (JACOMINE, 1996). No entanto, quando levamos em consideração que essa faixa abriga uma grande parcela da população do nosso país, que sofre dia-a-dia com os efeitos adversos da seca, torna-se necessário refletir minuciosamente sobre as possibilidades e estratégias de sobrevivência da população mediante essas adversidades climáticas.

$\mathrm{Na}$ relação entre as condições naturais do semiárido e a sua população Ab'Saber (2003) ressalta que mesmo diante do clima muito quente e sazonalmente seco, essa região possui uma paisagem própria que oferece possibilidade de uma convivência harmoniosa entre sua população e o meio ambiente. Eé com base nessa perspectiva da possibilidade de se estabelecer uma boa convivência nessa região que presenciamos nos últimos anos um elevado aumento do número de discussões e produções científicas voltadas para as discussões que caracterizam o semiárido brasileiro, bem como suas potencialidades e soluções para o estabelecimento de um convívio harmonioso nessa localidade mesmo diante dos efeitos adversos das secas. É o discurso da convivência com o semiárido que vêm sendo disseminado amplamente como forma de estímulo as pessoas que moram nessas áreas, para que elas compreendam as características climáticas de seu local de vivência, e, sobretudo, aprendam a conviver com os efeitos da secas sem comprometer as suas atividades socioeconômica e a qualidade de vida.

Vale ressaltar que a convivência com características climáticas peculiares como esta não é uma condição exclusiva do semiárido brasileiro, pois em outras partes do mundo podemos encontrar pessoas vivendo em áreas desertas ou ambientes extremamente gelados, em ambos os casos, as po- pulações precisaram se adaptar as condições climáticas para o convívio nessas áreas.

O IRPAA (Instituto Regional da Pequena Agropecuária Apropriada) defende a convivência com o semiárido como:

um modo de vida e produção que respeita os saberes e a cultura local, utilizando tecnologias e procedimentos apropriadas ao contexto ambiental e climático, constrói processos de vivência na diversidade e harmonia entre as comunidades, seus membros e o ambiente, possibilitando assim, uma ótima qualidade de vida e permanência na terra, apesar das variações climáticas. (IRPAA, 2015, p.1).

Nos últimos anos, a atuação das organizações da sociedade civil e de alguns órgãos públicos de pesquisa e extensão tem sido fundamentais para o trabalho direto com a população, juntamente com o Estado, no trabalho de fortalecimento dos vínculos de convivência com o semiárido. Segundo Silva (2003) esses atores vêm contribuindo para a superação do desafio de influenciar e disputar os processos de formulação de políticas públicas na região.

No semiárido brasileiro, as políticas públicas têm sido primordiais, tanto para o conhecimento da população local sobre o ambiente em que vivem e suas particularidades, quanto para o desenvolvimento de ações técnicas de convivência com os efeitos das secas. O conhecimento da população acerca do seu lugar de vivência é algo de grande importância para uma boa convivência, com a paisagem e as peculiaridades do semiárido. O conhecimento sobre a importância da água, por exemplo, e sobre as possíveis formas de captação, armazenamento e otimização da mesma são considerados muito úteis, principalmente para as pessoas que moram no campo, no entanto, nem todos conhecem com propriedade.

O conhecimento que a população dessa região tem sobre a água é muito pouco, ou seja, ela desconhece a origem e o sistema de atuação das chuvas; não sabe por que ocorrem as secas; não tem ideia de qual a quantidade de água necessária, por dia, mês e ano, à vida das pessoas e dos animais; não domina as diferentes formas de construir cisternas e/ou perfurar poços; e, finalmente, desconhece a importância da higiene da água. (PINTO e LIMA, 2005, p1)

O conhecimento de técnicas relacionadas à captação, armazenamento e utilização da água da chuva é de suma importância para a população do semiárido já que a distribuição das chuvas é considerada o principal dos problemas dessa região. Diante do desconhecimento dessas técnicas por parte de uma ampla parcela da população, a atuação de programas diversos provenientes de políticas públicas, tem sido essen- 
cial. Muitos desses programas proporcionam especialmente às familias carentes, a construção de cisternas de consumo e/ ou de produção, açudes, barragens, tanques, etc. e, além disso, oferecem formações para que os beneficiários possam utilizar essas benfeitorias da melhor forma para o seu sustento e também para o desenvolvimento de atividades agropecuárias.

Além de atuarem fortemente por meio das tecnologias sociais de captação, armazenamento e utilização da água, as políticas públicas no semiárido têm atuado amplamente em áreas como a produção agrícola, pecuária, indústrias, turismo, setor de serviços, etc. Para Pinto e Lima (2005) o aumento da oferta de atenção ao semiárido ocorrido por intermédio das políticas públicas de convivência com o semiárido tem por objetivo principal reverter o quadro de vulnerabilidade.

São muitas as ações que vêm sendo desenvolvidas e voltadas para o Semiárido. Parece que é o resgate e a devolução de uma dívida histórica, de um modelo de desenvolvimento que foi centrado no eixo Sul e Sudeste do país, e que abandonou as regiões mais necessitadas, resultando assim em um país com tantas desigualdades onde o desequilíbrio no desenvolvimento regional se faz tão claramente. (REIS, 2015 p. 4).

O aumento recente na oferta de políticas públicas para a convivência com o semiárido representa uma possibilidade para amenizar as perdas dessa região, sobretudo aquelas relacionadas ao problema da seca.

É importante ressaltar que as políticas públicas por si só não conseguirão resolver sozinhas todos os problemas do semiárido, a participação de uma expressiva parcela da população nesse processo é de grande relevância.Buarque (1999) ressalta que:

mesmo que as decisões de ordem política e econômica tenham um papel fundamental na reestruturação socioeconômica de um local ou município, se a intenção é a de alcançar o desenvolvimento local, é preciso haver alguma forma de mobilização e iniciativas dos atores locais concentradas num projeto coletivo. (BUARQUE, 1999, p. 24).

A participação ativa da população beneficiada por políticas públicas que visam a boa convivência no semiárido é de grande contribuição para o desenvolvimento e bom uso dos recursos provindos dessas políticas, isso é fundamental, pois as políticas públicas são, sobretudo, políticas sociais, porque beneficiam direta ou indiretamente as pessoas.

\section{METODOLOGIA E PROCEDIMENTOS ME- TODOLÓGICOS}

A pesquisa de abordagem quali-quantitativa, que visa apresentar e discutir aspectos quantitativos e qualitativos tem como método o hipotético dedutivo, que segundo Diniz e Silva (2008) pressupõem as bases teóricas dedutíveis a fenômenos particulares que refutarão ou corroborarão com a teoria em teste. Na pesquisa em questão a hipótese principal é que as políticas públicas têm contribuído significativamente para a população da zona rural do entorno do povoado de Barra Nova. Para a comprovação ou refutação dessa hipótese foi necessária a realização de uma pesquisa de campo. Tal procedimento se deu através de leituras para coleta de referencial teórico e posteriormente de visitas in lócus para coleta de dados, realização de entrevistas previamente semiestruturadas, observações nas propriedades de pessoas beneficiadas por alguma(s) dessa(s) política(s) pública(s), conversas informais com moradores do povoado, além de registros fotográficos.

De acordo com dados coletados na pesquisa de campo o povoado de Barra Nova está localizado a $12 \mathrm{~km}$ da sede do município de Várzea do Poço, suas Coordenadas Geográficas são: $11^{\circ} 35^{\prime} \mathrm{S}$ e $40^{\circ} 15^{\prime} \mathrm{W}$. De acordo com dados da Secretaria Municipal de Saúde a sede do povoado e seu entorno abriga uma população estimada de 450 habitantes. Os seus moradores têm na agricultura de subsistência, na pecuária, nas atividades oleiras e nos programas sociais do Governo as suas principais fontes de renda.

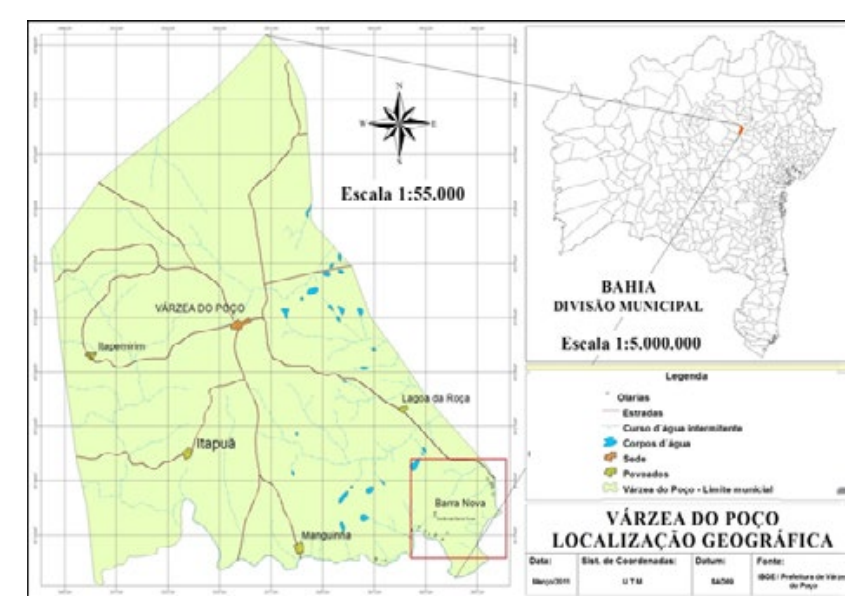

Figura2: -Várzea do Poço: localização geográfica com destaque para o povoado de Barra Nova

Fonte: Elaboração do autor

As entrevistas foram realizadas com representantes das familias contempladas com algum tipo de benfeitoria proveniente de políticas públicas direcionadas especificamente para convivência com o semiárido, e também com pessoas responsáveis pela gestão das políticas públicas nessa localidade. Nas entrevistas com os representantes das famílias buscamos investigar algumas das suas características socio- 
econômicas, aspectos produtivos das suas propriedades e a importância das tecnologias sociais de captação e armazenamento de água, bem como a significância das políticas públicas para o fortalecimento da produção e valorização do vínculo da família com a terra. Com os responsáveis pela gestão das políticas públicas nessa localidade buscamos identificar quais as políticas públicas que foram ofertadas a população dessa localidade nos últimos anos, as suas potencialidades, os critérios utilizados para a distribuição das mesmas, o suporte ofertado às familias beneficiadas, bem como as perspectivas futuras dessas políticas.

\section{RESULTADOS E DISCUSSÃO}

Constatamos de início que há pouco mais de 10 anos, uma grande parcela das familias de baixa renda, moradoras do povoado de Barra Nova e da zona rural do entorno dessa localidade foram beneficiadas diretamente com as tecnologias sociais de captação de armazenamento de água (cisternas de consumo ${ }^{1}$, cisternas de produção ${ }^{2}$, tanques de barreiro , barragens subterrâneas ${ }^{4}$, etc.), e unidades de produção animal, além de benefícios provenientes de programas de fortalecimento da agricultura familiar. Esses benefícios outorgados através de programas governamentais tem possibilitado à população dessa localidade a oportunidade de estabelecer um vínculo mais afetivo com o espaço de vivência, uma vez que estas políticas amenizaram o antigo e sério problema da falta da água, que obrigava, sobretudo os mais pobres, a percorrerem diariamente longos trechos a pé para buscarem água para o próprio consumo e de seus familiares.

Os recursos para a construção dessas tecnologias sociais nessa localidade provêm principalmente do Governo Federal, através do Programa Um Milhão de Cisternas, vinculado a redes como a ASA (Articulação Semiárido Brasileiro) e a programas do Governo do Estado da Bahia como o Programa Água Para Todos, desenvolvido através da CAR (Companhia de Desenvolvimento e Ação Regional). A atuação da Cáritas Diocesana de Ruy Barbosa ${ }^{5}$ como parceira dos Governos Estadual e Federal também tem sido fundamental para a gestão dessas políticas públicas na localidade de Barra Nova. Esse organismo tem estimulado na localidade o associativismo entre os moradores com a finalidade de buscar recursos e aprendizados a serem aplicados nas suas propriedades.

O perfil dos agricultores entrevistados é composto em sua maioria por indivíduos do sexo masculino. A maioria desses agricultores são proprietários dessas terras há mais de 10 anos e possuem renda média familiar mensal de um a dois salários mínimos. As principais fontes renda dos entre- vistados são os benefícios sociais como as aposentadorias e o Bolsa Familia (figura 3), além das atividades agropecuárias, que na maioria dos casos é destinada ao consumo próprio, e apenas o excedente é vendido; temos ainda aqueles que trabalham temporariamente ou como diaristas nas atividades agropecuárias em outras propriedades, e também aqueles que trabalham com a produção de tijolos, atividade bem significante na região, principalmente nos meses de estiagem. Muitos agricultores recorrem à produção de tijolos nos meses do ano em que não é possível plantar e trabalhar na agricultura, devido as desfavoráveis condições climáticas para o desenvolvimento da atividade agrícola (nesse caso, a falta de chuvas). Observamos o gráfico abaixo.

Programas sociais como as aposentadorias e o Bolsa família são apontados como as principais fontes de renda da população entrevistada. Esse fato reforça a fragilidade dos demais setores da economia nessa localidade e a consequente necessidade dos órgãos gestores conhecer as demandas da população local.

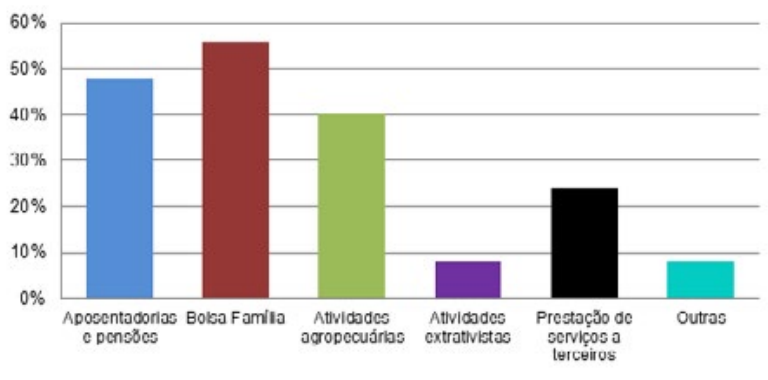

Figura3: - Principais fontes de renda das famílias do entorno do povoado de Barra Nova.

Fonte: Pesquisa de campo, 2016.

Ficou constatado pela pesquisa de campo que o tamanho da propriedade de terra varia, no entanto, apenas $20 \%$ das propriedades cujos proprietários foram entrevistados apresentam tamanho de área maior que 25 hectares, que na maioria dos casos destinam a produtividade agropecuária exclusivamente ao próprio consumo da família. Observe o gráfico da figura 4.

A produção de gêneros agrícolas alimentícios como, por exemplo, o feijão, o milho, a mandioca, a batata doce, a abóbora, dentre outros, mesmo em pequena escala, contribui para o sustento das familias. Geralmente esses produtos são plantados apenas uma vez por ano e algumas famílias estocam esses produtos para o consumo durante todo o ano. $\mathrm{O}$ quantitativo da produção agrícola nessas localidades tem diminuindo bastante nos últimos anos de acordo com os próprios agricultores. A maioria dos agricultores aponta 
a escassez de chuvas como um dos fatores determinantes para essa redução na produção agrícola. Muitos já perderam $100 \%$ da produção e por isso ficam receosos em investir intensivamente na atividade agrícola.

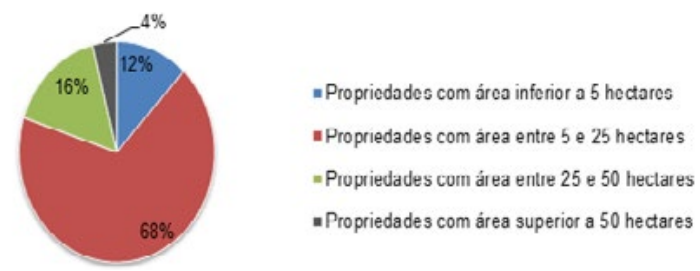

Figura4: - Área das propriedades rurais do entorno do povoado de Barra Nova (em hectares).

Fonte: Pesquisa de campo, 2016.

No que se refere à questão da água, procuramos compreender, através das conversas e entrevistas com os agricultores, algumas questões relacionadas à sua disponibilidade no local, distribuição, formas de captação e armazenamento, além das questões relacionadas às políticas públicas para a convivência com a seca.

Entendemos que a água é um bem precioso dotado de valor econômico e utilizado em grande escala pelas populações para atender diversas necessidades. Nesse contexto, a discussão acerca dos recursos hídricos torna-se de extrema relevância, haja vista que a falta de água é um problema que historicamente vem castigando a população do semiárido.

Segundo os moradores as chuvas são pontuais nessa localidade e é comum a ocorrência de um intervalo de quatro ou mais meses entre uma chuva e outra. Desse modo, muitos reservatórios de água, sobretudo os riachos, açudes e tanques das localidades acabam secando completamente. Os entrevistados, em sua totalidade, afirmaram que já sofreram as consequências da falta d'água. A famosa marcha carnavalesca "Lata d'água na cabeça" de 1952, do compositor Luís Antônio e conhecida pela voz da cantora Marlene, que retrata o dia-a-dia de uma mulher da zona rural que tinha que se deslocar a pé por longas distâncias para ir à busca de água, mesmo tendo que cuidar dos filhos pequenos, foi lembrada por uma agricultora entrevistada, que comparou a letra da música a uma situação vivenciada por ela na seca do ano de 1994, em que ela, juntamente com seus filhos pequenos tinham que se deslocar a pé por longas distâncias (às vezes superiores a $5 \mathrm{~km}$ ) em busca de água. Assim como ela, muitos outros relataram situações semelhantes, descreviam o quão era difícil morar naquela localidade mediante a falta de água até mesmo para beber. As pequenas aguadas, localizadas nas proximidades eram as primeiras a secar, então, era necessário percorrer longas distâncias em busca desse precioso líquido. Esse problema também atingiu os moradores da sede do po- voado de Barra Nova, que por diversos momentos tiveram a distribuição de água pela EMBASA (Empresa Baiana de água e Saneamento) suspensa.

Dentre os diversos períodos de estiagens, as secas de 1994 e de 2012 são consideradas pela população entrevistada como as mais intensas e recentes na localidade. Esses períodos foram marcados pelas severas estiagens e pelas suas trágicas consequências, sendo mais significativo: a morte de rebanhos, a perda total das lavouras e o esgotamento da maioria dos reservatórios de água. Apesar das semelhantes condições e consequências entre os dois períodos, houve um fator determinante para que os efeitos da seca de 2012 pudessem ser considerados menos desastrosos em relação ao da seca de 1994, esse fator é a presença das chamadas "tecnologias sociais" de captação e armazenamento de água, que estimulam a boa convivência da população daquela localidade e buscam aproximar o homem com o seu local de vivência através de soluções tecnológicas.

As cisternas (de consumo e de produção), os tanques de barreiros e as barragens subterrâneas são exemplos de tecnologias sociais de captação e armazenamento de água, utilizadas para a convivência com o semiárido, encontradas nas propriedades dos agricultores entrevistados. A dissipação dessas tecnologias tem sido positiva nessa região, pois tem pregado o discurso e a prática da política de convivência com o semiárido e não mais a simples busca pelo combate à seca, como fora feito em outros tempos, haja vista que a seca em alguns períodos temporais é uma condição ecológica natural dessa faixa do país e não uma catástrofe sem solução.

O discurso político fala agora de convivência com a seca e não mais de combate à seca, preconizando a necessidade da gestão dos recursos hídricos para a promoção do desenvolvimento sustentável, e a diminuição da fome e da miséria no Sertão. Parece um pequeno detalhe, mas representa grande diferença. É um deslocamento paradigmático, da ótica da negação das características ecológicas da região, para um enfoque de aceitação. Isso é básico para uma efetiva "convivência" do homem com o seu meio ambiente. (CHACON e BURSZTYN, 2005, p.2).

A mudança de paradigma deve vir acompanhada pela mudança nos hábitos dos moradores, que devem se conscientizar de que é possível viver bem no semiárido, trabalhar e produzir. $\mathrm{O}$ uso de sistemas eficientes de captação e armazenamento de água poderá solucionar uma série de antigos problemas e limitações relacionadas aos problemas constantes da falta de água. Apesar da distribuição irregular das chuvas, sempre é possível captar a água quando chove, armazená-la e, com isso, ter uma fonte segura durante o período seco, não somente como água potável, mas também para outros usos (GNADLINGER, 2015)

Grande parcela da água consumida na zona rural do 
entorno de Barra Nova vêm das tecnologias de captação e armazenamento de água da própria localidade, sendo as cisternas (de consumo e de produção) as mais expressivas. Consideradas um marco significativo pela população entrevistada, as cisternas, sobretudo aquelas de reserva de água potável para o consumo, contribuíram significativamente para a resolução do problema da falta de água nos períodos de estiagem. Elas estão presentes em 96,5\% das propriedades dos agricultores entrevistados e em quase sua totalidade foram adquiridas por meio de programas de políticas públicas de convivência com o semiárido. De acordo com Gnadlinger (2015) existe uma grande variedade de tipos de cisternas, no entanto as mais comuns na localidade são as cisternas de consumo.

As primeiras cisternas de consumo (figura 5) distribuídas na localidade e proveniente das políticas públicas foram construídas há pouco mais de 10 anos. Inicialmente o público-alvo principal dessas políticas era a população mais carente das áreas urbanas, posteriormente os moradores da zona rural do entorno do povoado passaram a ser beneficiados. Com o passar do tempo essas políticas atingiram uma ampla parcela da população do semiárido e os seus beneficiários reconhecem sua importância, sobretudo, para a resolução do problema da falta de água potável.

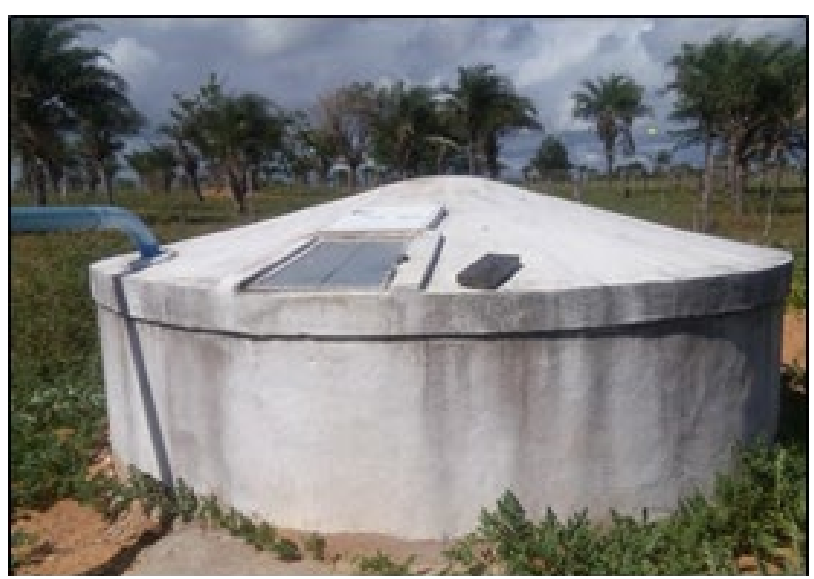

Figura 5: - Cisterna de consumo.

Fonte: Pesquisa de campo, 2016.

Tendo amenizado significativamente o problema da falta de água potável e objetivando ampliar o estoque de água das famílias do semiárido a ASA criou em 2007, o P1+2 (Programa Uma Terra e Duas Águas). Esse programa visa a oferta de condições de infraestrutura necessária para as famílias do campo produzirem garantindo a vida das plantas e dos animais. Além da cisterna de consumo o proprietário é beneficiado com uma tecnologia de captação de água para a produção, contribuindo assim para reforçar os aspectos socioeconômicos da população contemplada pelo programa.
No povoado de Barra Nova a implantação do Programa P1+2 ocorreu a partir do ano de 2013 e além das tecnologias de captação de água para o consumo, muitas famílias da localidade já contam com a presença de tecnologias voltadas para a dinamização da produção. Em Barra Nova houveram familias contempladas com as cisternas de calçadão (figura 6), barreiros de trincheira (figura 7) e também uma barragem subterrânea, ambas objetivam o aumento da produtividade agrícola e/ou pecuária e o consequente fortalecimento da agricultura familiar da criação de animais no semiárido. Além do P1+2, observa-se a existência de outro projeto significante de políticas públicas voltadas para a captação de água para a produção na localidade pesquisada, é o Programa Segunda Água, fruto da parceria entre o Consórcio Jacuípe, e a FATRES (Fundação de Apoio à Agricultura Familiar do Semiárido da Bahia).

O Consórcio Público de Desenvolvimento Sustentável do Território Bacia do Jacuípe foi fundado em 14 de outubro de 2011, com base na Lei Federal 11.107, após um longo processo de articulação para o desenvolvimento de política territorial nos 14 municípios do Território Bacia do Jacuípe/BA. O consórcio é uma associação pública de direito público que tem como objetivo a realização de serviços públicos nas áreas de abastecimento de água, esgotamento sanitário, drenagem e manejo de águas pluviais, gestão de resíduos sólidos, gestão ambiental compartilhada, habitação de interesse social, manutenção de estradas vicinais, implantação de abatedouros e frigoríficos regionais, capacitação de gestores municipais, educação profissional, saúde, projetos de apoio à agricultura familiar, a segurança alimentar e nutricional, entre outras. (Consorcio Bacia do Jacuípe)

A atuação desses programas e de suas políticas públicas tem contribuído para uma mudança de perspectivas para a população do povoado de Barra Nova, assim como na zona rural do seu entorno. Os períodos de escassez de chuvas já não são mais tão catastróficos, pois as cisternas de consumo e as demais tecnologias de captação de água têm suprido as necessidades básicas dessa população, no entanto, percebe-se através das entrevistas que o caráter produtivo dessas tecnologias destinadas a produção e a consequente geração de renda, ainda é bastante reduzido. Os beneficiários dessas tecnologias destinadas à produção participam obrigatoriamente de formações que visam orientá-los quanto ao uso e conservação dos reservatórios, preservação ambiental e potencialidades produtivas. Além de receberem a tecnologia para captação e armazenamento de água para a produção, a grande maioria dos proprietários beneficiados recebem kits produtivos de avicultura, apriscos, caprinocultura, de ovinocultura, bombeamento de água e de horticultura, de acordo com a opção de escolha de cada um.

De acordo com informações obtidas nas entrevistas com os agricultores, de dados da Secretaria Municipal de Saúde e da Secretaria Municipal de agricultura podemos consta- 
tar que 32 propriedades rurais foram beneficiadas com algum tipo de tecnologia social. Trata-se de um número significativo, que representa um percentual superior a $90 \%$ de todas as propriedades do entorno de Barra Nova.

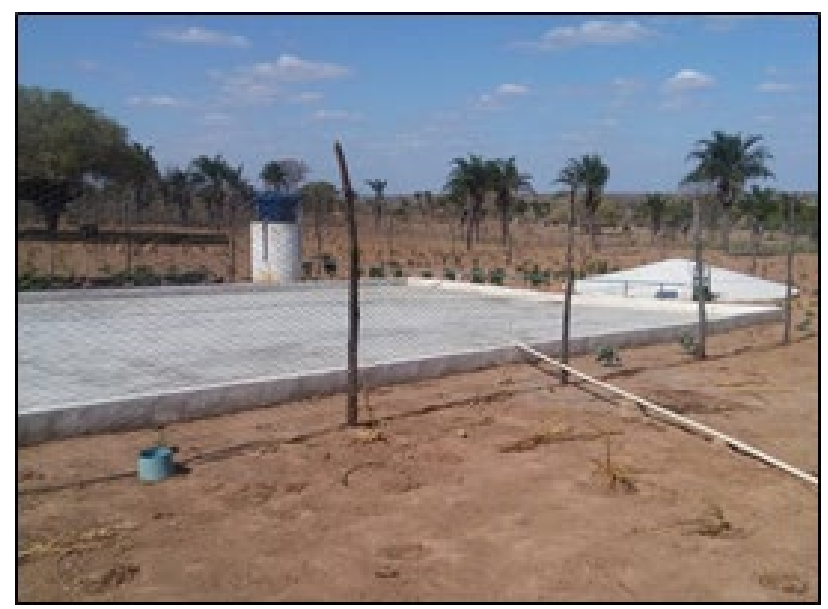

Figura 6: Cisterna de calçadão equipada com sistema de irrigação para hortaliças.

Fonte: Pesquisa de campo, 2016.

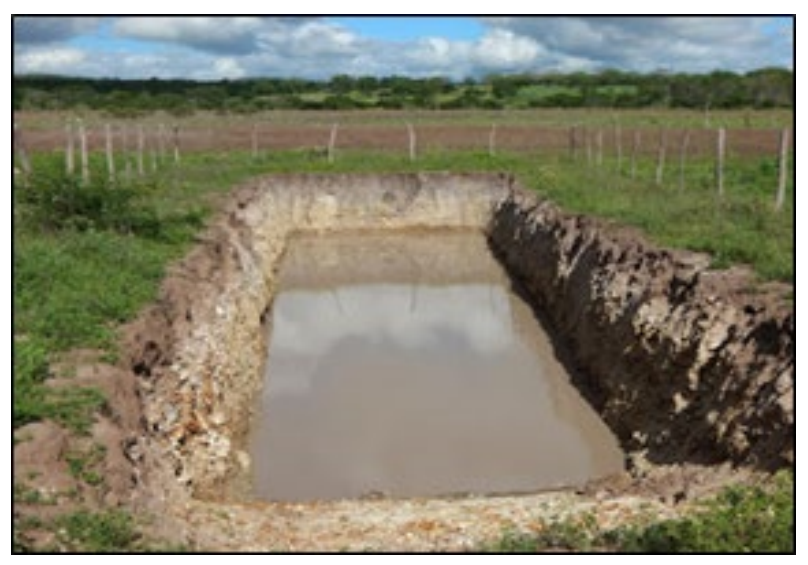

Figura 7: Barreiro de Trincheira.

Fonte: Pesquisa de campo, 2016.

Através das entrevistas realizadas com o Secretário Municipal de Agricultura de Várzea do Poço, o Sr. Valter João dos Santos e com a presidenta de uma das associações do local, a Sra. Zilma Pereira de Matos Nunes, representantes locais da gestão desses projetos na localidade, podemos compreender um pouco mais sobre as potencialidades das políticas públicas para a convivência com os efeitos da seca naquela localidade.

O Sr. Valter João dos Santos enfatizou algumas das ações que a Secretaria Municipal de Agricultura através de suas parcerias tem realizado naquela localidade para o incentivo a convivência com o semiárido. $\mathrm{O}$ mesmo ressaltou a importância das cisternas de consumo para a resolução do problema da falta de água para beber, e também a relevância das cisternas de produção (cisternas de calçadão), além dos barreiros de trincheira e das barragens subterrâneas existentes nas localidades. O caráter produtivo, segundo o Secretário, é primordial, pois além de reforçar a identidade da população com lugar em que vive, oferta opções de produção para subsistência e desenvolvimento socioeconômico, a partir da venda do excedente.

Além das políticas públicas de oferta de tecnologias sociais de captação e armazenamento de água, alguns moradores dessas localidades já foram beneficiados com outros programas e ações governamentais como: o Garantia Safra, que oferece insumos produtivos para a agricultura familiar e objetiva o aumento da produção e produtividade das propriedades rurais resultando na ampliação da renda, além de segurança alimentar e nutricional das famílias beneficiadas; Financiamentos do Pronaf, destinados a compra de rebanhos e insumos; E também a doação de mudas de Palma Lisa para o plantio e utilização como ração dos rebanhos, sobretudo nos períodos de seca.

A Sra. Zilma Pereira de Matos Nunes, é presidente de uma associação de moradores de Barra Nova e região circunvizinha: a associação Cáritas em busca de projetos (fundada no ano de 2011). Ela ressaltou a importância do associativismo para a obtenção de benefícios para a população de modo geral. Moraes e Curado (2004) ressaltam que associações como essa são sociedades formais criadas com o intuito de fortalecer ações e integrar esforços de agricultores e seus familiares em busca da melhoria do processo produtivo e da própria comunidade a qual eles fazem parte. Para as conquistas sociais a participação social é um fator de grande relevância, nesse contexto, os associados, unidos têm buscado junto aos governos Municipal, Estadual e Federal, benefícios voltados para a produção agropecuária em suas propriedades. A obtenção de cisternas (de consumo e produção) e dos barreiros de trincheira para os associados representam uma grande conquista para os associados.

A Sra. Zilma e o Sr. Valter ressaltaram nas suas falas a relevância das formações pela qual os beneficiários desses programas passam. As formações são necessárias e contribuem para que o beneficiário e seus familiares compreendam algumas questões pertinentes ao planejamento, instruções de uso e conservação das tecnologias de armazenamento de água e otimização da infraestrutura.

\section{CONSIDERAÇÕES FINAIS}

Diante da avaliação desenvolvida acerca da atuação das políticas públicas de convivência com o semiárido podemos compreender que nos últimos anos essas políticas têm se intensificado mediante a compreensão das condições geoclimáticas locais e da mudança de paradigmas que desvincu- 
lam a seca como um fator catastrófico, tratando-a como uma característica natural que exige adaptação da população local para a boa convivência e para o estabelecimento de atividades socioeconômicas.

Na zona rural do entorno do povoado de Barra Nova, Várzea do Poço - BA, localidade em que foi realizada a pesquisa de campo, foi possível identificar que as tecnologias sociais de estímulo a convivência com o semiárido, implantadas na localidade gradativamente a partir de 2004, amenizaram significativamente os problemas relacionados a falta d'água, sobretudo para o consumo direto pelas familias. De acordo com relatos dos moradores dessa localidade as cisternas de consumo são as principais responsáveis por essa mudança. Antes de serem beneficiados com as cisternas eram frequentes nos períodos de estiagens os deslocamentos por longos trajetos, às vezes superiores a $5 \mathrm{~km}$, para irem à busca de água para beber e para o consumo geral da família.

Além das cisternas de consumo podemos constatar a existência de outras tecnologias sociais provenientes de políticas públicas destinadas a produção, principalmente para a produção de gêneros agrícolas e para o desenvolvimento da pecuária em pequena escala, destinados principalmente para a subsistência. $\mathrm{Na}$ localidade pesquisada as principais dessas tecnologias são as cisternas de calçadão, os barreiros de trincheira e também uma barragem subterrânea. Essas tecnologias provêm de políticas públicas mais recentes, uma grande parcela dos entrevistados só foi contemplada com essas tecnologias há menos de dois anos, desse modo, o caráter produtivo ainda não é expressivo e apenas uma pequena minoria da população entrevistada consegue produzir para a subsistência da familia e simultaneamente produzir para comercializar.

Além das tecnologias sociais, outras políticas públicas foram mencionadas pelos entrevistados como programas de incentivo a produtividade, financiamentos e doação de mudas. Ambas foram avaliadas como positivas para uma melhor convivência da população com as peculiaridades do local. Através dessa avaliação podemos constatar que as políticas públicas de convivência com a seca têm sido eficientes principalmente por garantir o armazenamento de água potável para a população beneficiada evitando assim, as longas peregrinações em busca desse líquido tão precioso no semiárido.

A intensificação e incrementacão dessas políticas com destaque para o caráter produtivo também é relevante, pois a população não quer apenas água para beber, ela demanda também água para o desempenho de outras atividades importantes e típicas para quem mora e vive do campo, que são a agricultura e a pecuária. Em Barra Nova o caráter produtivo necessita ser reforçado, para que os pequenos agricultores possam aumentar a sua produtividade e consequentemente reforçar o caráter socioeconômico da agropecuária local.

As formações, pelas quais os proprietários beneficiados por essas políticas públicas passam, são essenciais e precisam ser reforçadas com o proposito principal de contribuir para a formação dos proprietários, para que eles possam adquirir conhecimentos técnicos e específicos para lidarem com as tecnologias e, sobretudo para o desenvolvimento da autonomia sobre o seu espaço de vivência.

\section{REFERÊNCIAS BIBLIOGRÁFICAS}

AB'SÁBER, A. Os Domínios de natureza no Brasil: potencialidades paisagísticas. São Paulo: Ateliê Editorial, 2003.

ASA. Articulação do Semiárido Brasileiro. Disponível em: <http://www.asabrasil.org.br/acoes/p1-2>. Acesso em 10 de jan. de 2016.

BRASIL. Ministério da Integração. Portaria $\mathbf{n}^{\circ} 89$ de 16 de março de 2005. Atualiza a relação dos municípios pertencentes à região Semiárida do Fundo Constitucional de Financiamento do Nordeste - FNE. Brasilia: MI, 2005.

BRITO, L. T. L.; SILVA, A. S.; PORTO, E. R.; AMORIM, M. C. C. de; LEITE, W. M.. Cisternas Domiciliares: água para consumo humano. In: Potencialidades da água de chuva no Semiárido brasileiro. Petrolina-PE: Embrapa Semiárido, 2007.

BUARQUE, S. C. Metodologia de Planejamento do Desenvolvimento Local e Municipal Sustentável. Brasília: Instituto Interamericano de Cooperação para a Agricultura (IICA), 1999.

CAMPOS, J. N. B. Secas e políticas públicas no semiárido: ideias, pensadores e períodos. In: Sociedade e Ambiente. Programa de Recursos Hídricos, Universidade Federal do Ceará, Fortaleza/CE, Brasil, Estudos Avançados, vol.28, no 82, São Paulo Out/Dez. 2014. Disponível em: <http://www.scielo.br/scielo.php?pid=S0103$-40142014000300005 \&$ script $=$ sci_arttext $>$. Acesso em 10 de jan, de 2016.

Cáritas Diocesana de Ruy Barbosa. Disponível em: $<$ http://caritasruybarbosa.blogspot.com.br/>. Acesso em 10 de jan de 2016. 
CHACON, S. S.; BURSZTYN, M. Análise das políticas públicas para o sertão semi- árido: promoção do desenvolvimento sustentável ou fortalecimento da pobreza? In: VI Encontro da Sociedade Brasileira de Economia Ecológica, 2005, Brasília-DF. VI Encontro da Sociedade Brasileira de Economia Ecológica. Brasília-DF: ECO-ECO, 2005. Anais.... Disponível em: <http://www.ecoeco.org.br/ conteudo/publicacoes/encontros/vi_en/artigos/mesa5/ analise_das_politicas_publicas.pdf $>$. Acesso em 10 de jan. de 2016.

CONSORCIO BACIA DO JACUÍPE. Disponível em: < http://cdsjacuipe.com.br/o-consorcio.php>. Acesso em 10 de jan de 2016.

DINIZ, C. R; SILVA I. B. Metodologia científica. Campina Grande; Natal: UEPB/UFRN - EDUEP, 2008.

GNADLINGER, J. Água de chuva no manejo integrado dos recursos hídricos em localidades semiáridas: aspectos históricos, biofísicos, técnicos, económicos e sociopolíticos. Captação, manejo e uso de água de chuva, Campina Grande - PB, 2015. Disponível em: <http://www.irpaa. org/fotos/file/gnadlinger_captacao_chuva_compressed. pdf>. Acesso em 10 de jan. de 2016.

GOBERT; MULLER In, VAZ., L.G.D.; Políticas públicas. Revista nova Atenas de educação e tecnologia. Revista eletrônica do departamento. Acadêmico de ciência da saúde Educação física e esportes - Biologia - Segurança do trabalho. Vol. 10, nº 01, jan./jun./2007.

HEIDEMANN, F. Do sonho do progresso às políticas de desenvolvimento. In: HEIDEMANN, F; SALM, J. F. (Org.). Políticas Públicas e Desenvolvimento: bases epistemológicas e modelos de análise. 2.ed. Editora Universidade de Brasília, 2010. cap. 1, p. 23-40.

HÖFLING, E. M. Estado e Políticas (Públicas) Sociais. In: Cadernos Cedes, ano XXI, no 55, novembro/2001, pp. 30-41. Disponível em: <http://www.scielo.br/scielo. php?pid=s0101-32622001000300003\&script $=$ sci_art text>. Acesso em 10 de jan de 2016.

IBGE. Censo Demográfico 2010. Disponível em: <http://www.censo2010.ibge.gov.br>

IRPAA. Convivência com o semiárido. Disponível em: http://www.irpaa.org/modulo/convivencia-com-o-semia- rido. Acesso em 02 de mar de 2015.

JACOMINE, P. K. T. Solos sob caatingas: características e uso agrícola. In: ALVAREZ V., V.H.; FONTES, L.E.F.; FONTES, M.P.F. O solo nos grandes domínios morfoclimáticos do Brasil e o desenvolvimento sustentável. Viçosa, SBCS-UFV, 1996. 930p.

MORAES, E. G. de; CURADO. F. F. Os limites do associativismo na agricultura familiar de assentamentos rurais em Corumbá, MS. IV Simpósio sobre Recursos Naturais e Sócio-econômicos do Pantanal. Anais... Corumbá/ MS: 2004. Disponível em: <http://www.cpap.embrapa. $\mathrm{br} /$ agencia/simpan/sumario/artigos/asperctos/pdf/ socio/323SC_CURADO_8_OKVisto.pdf $>$. Acesso em 10 de jan. de 2016.

PINTO, E. B. ; LIMA, M. J. A. O programa de convivência com o Semiárido brasileiro e sua influência na mudança de hábitos e valores. II Congreso Iberoamericano sobre Desarrollo y Médio Ambiente. Anais... Puebla/México, out/2005.

REIS, E. S. Educação para a convivência com o semiárido: desafios e possibilidades. Disponível em: http:/ / www.ppgesa.uneb.br/arquivos/ECS-DP.pdf. Acesso em 10 de jan. de 2016.

SECCHI, L. Políticas Públicas: conceitos, esquemas de análise, casos práticos. São Paulo: Cengage Learning, 2010 .

SILVA, R. M. A. da. Entre dois paradigmas: combate à seca e convivência com o semi-árido. Sociedade e estado, vol. 18, Brasília Jan./Dec. 2003. Disponível em: <http://www.scielo.br/scielo. php?pid=S0102-69922003000100017\&script=sci_arttext>. Acesso em 10 de jan. de 2016.

SOUZA, C. Políticas Públicas: uma revisão da literatura. Revista Sociologias, ano 8, $n^{\circ} 16$, Porto Alegre: 2006, p. $20-45$.

SUDENE- Superintendência de Desenvolvimento do Nordeste. - Plano de Aproveitamento Integrado dos Recursos Hídricos do Nordeste. Recife, PE: SUDENE, 1980. 
Notas de Fim:

1- Essa cisterna possui capacidade de armazenamento de $16 \mathrm{~m}^{3}$ de água, suficientes para atender às necessidades básicas de uma família com cinco pessoas, por um período sem chuvas de 240 dias (BRITO et al., 2007).

2- Cisternas com maior capacidade de armazenamento de água destinada à atividades agropecuárias de subsistência.

3- São tanques longos, estreitos e fundos escavados no solo. Com capacidade para armazenar, no mínimo, 500 mil litros de água. (ASA).

4- É construída em áreas de baixios, córregos e riachos que se formam no inverno, que é a época chuvosa no Semiárido. Sua construção é feita escavando-se uma vala até a camada impermeável do solo, a rocha. Essa vala é forrada por uma lona de plástico e depois fechada novamente. Dessa forma, cria-se uma barreira que "segura" a água da chuva que escorre por baixo da terra, deixando a área encharcada. (ASA)

5- A Cáritas é um organismo da Conferência Nacional dos Bispos do Brasil (CNBB) de promoção e atuação social que trabalha na defesa dos direitos humanos, da segurança alimentar e do desenvolvimento sustentável solidário. Na localidade pesquisada a Cáritas diocesana de Ruy Barbosa tem desenvolvido um trabalho significativo de convivência da população com os efeitos da estiagem.

6- É uma tecnologia que capta a água da chuva por meio de um calçadão de cimento de $200 \mathrm{~m}^{2}$ construído sobre o solo. Com essa área do calçadão, $300 \mathrm{~mm}$ de chuva são suficientes para encher a cisterna, que tem capacidade para 52 mil l. (ASA)

\title{
Correspondência do autor:
}

\author{
Johnny Gomes de Oliveira
}

e-mail: johnny.de.oliveira@hotmail.com

Artigo recebido em: 26/09/2016

Revisado pelo autor em: 01/03/2017

Aceito para publicação em: 14/04/2017 